\title{
A Study of Microcapsules Containing Psidium Guajava Leaf Extract for Antibacterial Agent on Cotton Fabric
}

\author{
Jiraphorn Katewaraphorn and Arunee Kongdee Aldred
}

\begin{abstract}
Psidium Guajava Linn. leaf extract containing phenolic compounds are known for antimicrobial activity. This study's objective was to prepare antibacterial cotton fabric by using microcapsules containing Psidium guajava Linn. leaf extract. Microcapsules containing Psidium guajava Linn. leaf extract were prepared by in situ polymerization using urea and formaldehyde for encapsulation. Both Psidium guajava Linn. leaf extract and microcapsules containing Psidium guajava Linn. leaf extract have been applied to cotton fabric by direct printing with a binder. The qualitative antibacterial assessment of the fabric was performed according to AATCC 147-2004 against Escherichia coli and Staphlococcus aureus as test organisms. The antibacterial tests proved that the cotton fabric finished with microcapsules containing Psidium guajava Linn. leaf extract showed antibacterial activity against Staphlococcus aureus, but was not effective against Escherichia coli
\end{abstract}

Index Terms-Poly(urea-formaldehyde), microcapsule, Psidium guajava Linn., antibacterial textile.

\section{INTRODUCTION}

Currently, scientific advancement is used for the development of innovative textile products to produce functional textiles inclusive of fragrances, dyes, insect repellants, phase-change materials, antimicrobial agents, and fire retardant. The consumer is increasing in awareness and concern for the safety of products [1]. Thus, there is a need to develop textiles that are resistant to microbes as the textile substrates find various applications such as masks, hospital covers, and surgical gowns apart from conventional apparel usage [2]. Various antimicrobial technologies have been developed to protect various materials from microbial damage and to prevent microbial infection [3]. Hence, textiles are treated with various compounds. Many commercial products are currently available in the market with a range of antimicrobial properties, under different trade names of the textile industry. Most of the products are made from synthetic agents; for example, organo-metallics, phenols, quaternary ammonium salts and organosilicons. Even though the synthetic antimicrobial agents show high effectiveness for inhibiting the microbes, they are hazardous to human health [4]. Different chemicals and heavy metals are non-biodegradable. For this reason, natural extracts for finished fabrics are being considered as an alternative

Manuscript received April 10, 2015; revised May 25, 2015. This work was financially supported by the Office of the Higher Education Commission (OHEC). The author was funded by a scholarship from Rajabhat Uttaradit University.

Jiraphorn Katewaraphorn and Arunee Kongdee Aldred are with the Applied Chemistry Program, Faculty of Science Maejo University, 50290 Thailand (e-mail: aoaoe27@ hotmail.com, akongdee@hotmail.com). antibacterial agent for this work.

Psidium guajava Linn. (family Myrtacae) is commonly called guava [5]. Guava has been shown to have several biological activities such as antidiabetic, anticough, antioxidant, antibacterial and antispasmotic properties [6]. Most of the pharmacological and chemical work has been carried out on the leaf, since the leaf of the guava is rich in flavonoids and phenols including terpenoids, tannins, essential oils, chlorophyll and saponins [7]. The aqueous and alcoholic extracts of guava (root as well as leaves) were found to have inhibitory effects on the growth of Staphylococcus aureus, Streptococcus mutans, Pseudomonas auruginosa, Salmonella enteritidis, Bacillus cerus, Proteus spp., Shigella spp., and Escherichia coli, causal agent of intestinal infections in humans. These effects were examined using the in vitro agar well diffusion method [8]. In another study, aqueous and methanolic extracts of the leaves are effective inhibitors of growth spore formation and enterotoxin production of Clostridium perfringens type A [9]. Its antimicrobial activity was beneficial when applied as an antimicrobial agent in textiles.

Microencapsulation technology is a well-known technique for finishing textiles. This technique is based on active compounds being encapsulated using a material wall for long-acting release and protection from the environment [10]. Encapsulation in a poly(urea-formaldehyde) shell (PUF) has proven to be one of the most versatile and widely used encapsulation approaches. Microcapsules (MCs) are produced by the polymerization and deposition of the UF polymer at the interface of the suspended emulsion droplet. Polymerization of the shell wall occurs in the aqueous phase until a critical molecular weight is achieved and the polymer phase separates and is deposited at the encapsulent-aqueous interface [11]. The deposited polymer forms the shell wall of the microcapsule. The increase in molecular weight of the urea-formaldehyde resin occurs under acidic conditions [12]. Ammonium chloride and ammonium sulfate are the most widely used catalysts and resorcinol is used as a cross-linking agent.

Cotton is widely used as a textile material, as it is soft and comfortable to wear. However, its porous hydrophilic structures retain water, oxygen, and nutrients, which provides a perfect environment for the growth of microorganisms [14]. N. T. Hein, S. S. Hnin, and D. H. Htay studied the effect of antimicrobial agents from Aloe Vera gel on bleached cotton fabric. This study revealed that the antimicrobial activity of Aloe Vera gel treated fabric was excellent for inhibiting Pseudo and E. coli and good for inhibiting B. aureus and B. pumilus bacteria, but it could not inhibit the growth of $S$. aureus and Candi [15]. S. Sharaf, A. Higazy, and A. Hebeish 
applied propolis extract with glyoxal and $\mathrm{Al}_{2}\left(\mathrm{SO}_{4}\right)_{3}$ catalyst using the pad-dry method to produce a cotton textile with superior antibacterial activity, water repellant properties, and UV protection [16]. Plant extracts from the Jatropha Curcas leaf were used to treat cotton fabrics by the direct application method and antimicrobial activity was determined by an agar plate test. The results showed that the plant extract demonstrated a considerable zone of inhibition to $S$. aureus and acted as a bactericide [17]. The extract of pomegranate (Punica granatum) was used for dyeing cotton fabric. The antimicrobial activity was assessed qualitatively by the disc diffusion method and AATCC 147, and was quantitatively tested by AATCC 100 against $E$. coli and $S$. aureus. Pomegranate extract displayed excellent antibacterial activity against both of the test organisms [18]. Moreover, acetic acid soluble material was isolated from the cell wall of Mucor rouxii DSM-1191 and applied on cotton fabrics. The results showed that Mucor rouxii DSM-1191 has excellent antibacterial activity against $E$. coli and M. luteus [19].

The aim of this work was the encapsulation of guava leaf extracts into urea-formaldehyde microcapsules by in situ polymerization, in order to develop an eco-friendly natural antimicrobial finish in textiles. Cotton was finished with an antibacterial agent extracted from the guava leaf in this work. In addition, the finished fabric was assessed for antibacterial activity using AATCC 147-2004 against test organisms of Staphylococcus aureus (S. aureus) and Escherichia coli (E. coli). S. aureus is a major disease-causing bacteria that exists in the armpit, inner elbow, between the mid-buttocks, the sides of the groin, and the bottom of the head. E. coli is also considered a potential pathogen and resides mainly in the small intestine. However, it can also be found in the inguinal and perineal areas contaminated by urine and feces [20].

\section{PROCEDURE}

\section{A. Materials}

Urea, 36\% formaldehyde, and acetic acid were purchased from Prolab. Ammonium acetate and Folin-Ciocalteu reagent were purchased from QRëC®. Polyvinyl alcohol (PVA) and zinc nirate were provided by Ajax Finechem PTY. Ammonium chloride was obtained from Rankem, and Resorcinol from HIMEDIA Labaratories Pvt. Helizarin, Fixapret F-Eco and Condensol were obtained from BASF. Triplicate soy gar and Triplicate soy broth were provided by Difco, and Acetylacetone by ACROS. Carboxymethyl cellulose (CMC) was obtained from Sigma Aldrich.

\section{B. Preparation of Guava Leaf Extract}

The fresh leaves of Psidium guajava L. were collected from Chiang Mai. Then, the leaves were washed to remove debris and dried at $50^{\circ} \mathrm{C}$ for 24 hours in an oven. After being completely dried, the leaves were crushed into small pieces. Samples were extracted with distilled water in a ration of $1: 15$ at $60^{\circ} \mathrm{C}$ for 1 hour. The extracts were sieved through cheesecloth followed with Whatman No.3 filter paper. The filtrates were concentrated by water evaporation and freeze-dried at $-20^{\circ} \mathrm{C}$. Crude extracts were stored at $4{ }^{\circ} \mathrm{C}$ for further application.

\section{Preparation of MCs Containing Guava Leaf Extract}

PUF MCs containing guava leaf extract were prepared by in situ polymerization according to the procedure of Suryanarayana [21] with modifications. Firstly, $5 \mathrm{~g}$ of urea, $0.5 \mathrm{~g}$ ammonium chloride and $0.5 \mathrm{~g}$ resorcinol were dissolved in $260 \mathrm{ml}$ distilled water. Secondly, $10 \mathrm{ml}$ of $5 \% \mathrm{wt}$ aqueous solution of PVA was added into the solution and the $\mathrm{pH}$ of the solution was adjusted to 3.5 with $5 \%$ hydrochloric acid. After $5 \mathrm{~g}$ extract was loaded into the solution for $10 \mathrm{~min}, 12 \mathrm{ml}$ of $36 \%$ wt formaldehyde solution was added. The reaction was constantly stirred at $800 \mathrm{rpm}$ and heated at $55^{\circ} \mathrm{C}$ for 4 hours. The obtained MCs were subsequently filtered with Whatman No.3 paper under a vacuum and washed with distilled water. Finally, the prepared MCs were dried at room temperature and stored under a vacuum condition.

\section{Characterization of Microcapsules}

The morphology of the MCs was observed using a scanning electron microscope (SEM, 5410LV JEOL). The MC samples were dispersed in distilled water and sonicated for 30 min. After that, one drop of the MC dispersion was placed on the surface of a double-faced black adhesive tape attached to a stainless steel stub and dried at $50^{\circ} \mathrm{C}$ for 1 hour. The samples were sputtered with a thin layer of gold.

The MCs containing guava leaf extract were analyzed using a Fourier-transform infrared spectrometer (FTIR, Perkin Elmer) to identify the chemical structure of the samples. The samples mixed with potassium bromide $(\mathrm{KBr})$ were ground and analyzed in $\mathrm{KBr}$ pellet form. The size of the MCs was also analyzed using a particle size analyzer (Mastersizer, MALVERN).

\section{E. Finishing of Cotton Fabric}

Both the guava leaf extract and the MCs containing guava leaf extract were applied to cotton fabric using the printing method. $50 \mathrm{~g} / \mathrm{l}$ of guava leaf extract/MCs was mixed with $2 \%$ wt of CMC, $50 \mathrm{~g} / \mathrm{l}$ of Helizarin, $50 \mathrm{~g} / \mathrm{l}$ of Fixapret F-Eco, 20 $\mathrm{g} / \mathrm{l}$ of Condensol and $10 \mathrm{~g} / \mathrm{l}$ of zinc nitrate. The cotton fabric was coated with the mixture using a printing machine (Kidd + Zigrino). The fabric was dried at $105^{\circ} \mathrm{C}$ for 90 seconds and cured at $175^{\circ} \mathrm{C}$ for 45 seconds. The fabric was washed with water before further testing. The modified surface of the finished fabric was observed using SEM.

\section{F. Antibacterial Activity Testing}

The finished fabric was assessed for antibacterial activity according to modified AATCC147-2004 [22]. The bacteria species of Gram positive Eschericia coli and Gram negative Stapphylococcus aureus were used in this standard. The cell concentration of bacteria for this work was $10^{8} \mathrm{CFU} / \mathrm{ml}$. Nutrient agar plates were streaked with 5 lines of bacteria from an inoculation loop. Then, the fabric samples were placed over the incubated agar culture. After incubation at $37^{\circ} \mathrm{C}$ for $18-24$ hours, the inhibition zone was observed.

\section{G. Determination of Formaldehyde Content}

The method for determination of free formaldehyde was the 2,4-pentanedion method according to BS EN ISO 14184-1:1999 part I Annex A [23]. Firstly, a $0.5 \mathrm{~g}$ fabric sample was put into a $250 \mathrm{ml}$ flask and followed with $20 \mathrm{ml}$ of deionized water. The flask was covered with a stopper and 
heated in a water bath at $40^{\circ} \mathrm{C}$ for 1 hour with a laboratory shaker. Then, the warm solution was filtered into another flask through a Whatman filter. After $5 \mathrm{ml}$ of solution sample was transferred into a tube, $5 \mathrm{ml}$ of acetylacetone solution was added into the tube, which was covered with a stopper and shaken. The mixture was kept first in a water bath at $40^{\circ} \mathrm{C}$ for $30 \mathrm{~min}$ and then was left at room temperature for $30 \mathrm{~min}$. Blank reagent was prepared by adding $5 \mathrm{ml}$ of acetylacetone solution to $5 \mathrm{ml}$ deionized water and treating it the same way. The absorbance was measured at $415 \mathrm{~nm}$ using a spectrophotometer (U2001 Hitashi, Japan). Formaldehyde solution $(0.15-6.00 \mu \mathrm{g} / \mathrm{ml})$ was prepared as the calibration solution. Each test was performed in triplicate.

\section{RESULTS AND DISCUSSION}

\section{A. Characterization of MCs}

First of all, encapsulation of guava leaf extract in a PUF shell is carried out when the $\mathrm{pH}$ becomes acidic, is heated to $55^{\circ} \mathrm{C}$, and reacts with urea and formaldehyde resulting in a PUF. In the initial step of polymerization, the urea-formaldehyde molecule is rich in polar groups and is water compatible. The product of this step is called methyl urea. Next, the number of polar groups is gradually reduced as the molecular weight of the polymer increases. Finally, the hydrophilicity of the PUF molecule is reduced leading to separation from the aqueous phase, and droplets of $\mathrm{MC}$ powder are received [24]. MC powder without extract is white, whereas MC powder containing extract is brown.

The structure of PUF MCs was investigated using FTIR to confirm the existing core material and guava leaf extract. The FTIR spectrum of the guava leaf extract, PUF shell, and PUF MCs containing guava leaf extract are presented in Fig. 1. The spectra of the PUF shell and PUF MCs containing guava leaf extract show a similar pattern: peaks of $\mathrm{C}=\mathrm{O}$ stretching vibration at $1650 \mathrm{~cm}^{-1}, \mathrm{~N}=\mathrm{H}$ stretching vibration at $1554 \mathrm{~cm}^{-1}$, and $\mathrm{C}-\mathrm{N}$ stretching vibration at $1245 \mathrm{~cm}^{-1}$. These spectrums confirm the formation of the PUF wall of the MCs. Furthermore, the presence of peaks at $1444 \mathrm{~cm}^{-1}$ and 1118 $\mathrm{cm}^{-1}$ in the spectrum band of PUF MCs containing guava leaf extract correspond to the $\mathrm{C}-\mathrm{H}$ stretching vibration and $\mathrm{C}-\mathrm{C}$ stretching vibration in the spectrum of guava leaf extract. Along with the $\mathrm{O}-\mathrm{H}$ peak at $3700-3000 \mathrm{~cm}^{-1}$, it shows a broader band which corresponds to the $-\mathrm{OH}$ group in phenolic compounds. It shows that the guava leaf extract is successfully encapsulated in the PUF shell.

Fig. 2 illustrates SEM images of MCs without extracts and MCs containing guava leaf extract. MCs without extract have a spherical particle and smooth outer surface. When the extract was loaded into the PUF, the MCs are larger and have an irregular shape. Additionally, the MCs tend to agglomerate to form a large mass of small particles.

Fig. 3 reveals the size distribution of MCs. The size of MCs without extract is distributed into 2 ranges: a large group of 8-50 micrometers and a smaller group of 50-140 micrometers. The diameter of MCs containing extract was larger and ranged from 40-180 micrometers. This may be caused by encapsulation of the extract by PUF.

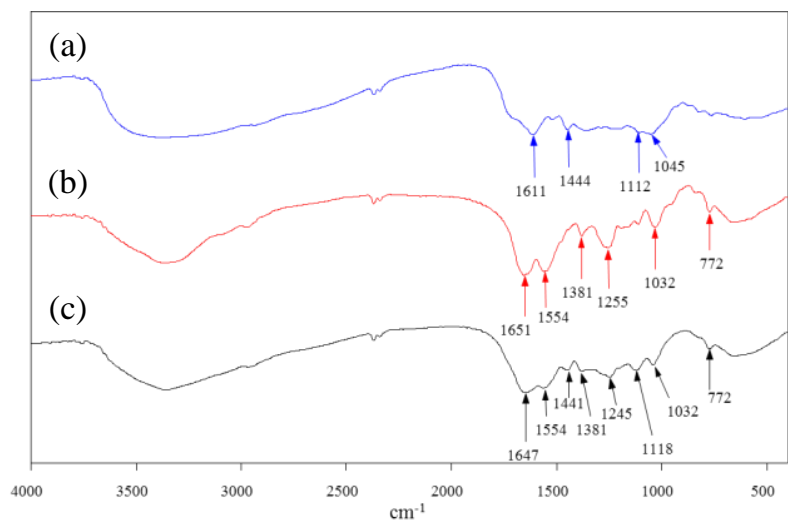

Fig. 1. FTIR spectra of (a) guava leaf extract (b) PUF shell (c) PUF MCs containing guava leaf extract.

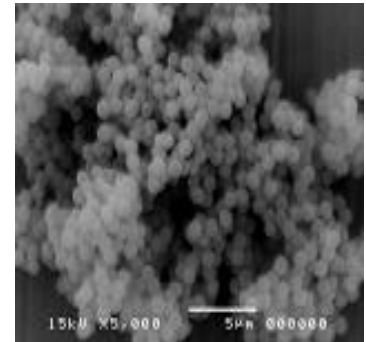

(a)

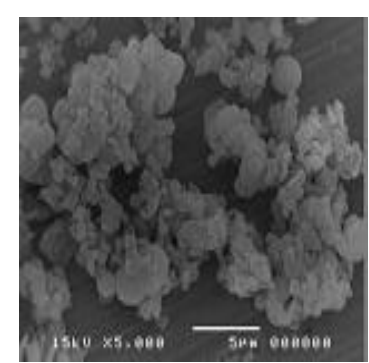

(b)
Fig. 2. SEM images of (a) PUF MCs without extract; (b) PUF MCs containing guava leaf extract.

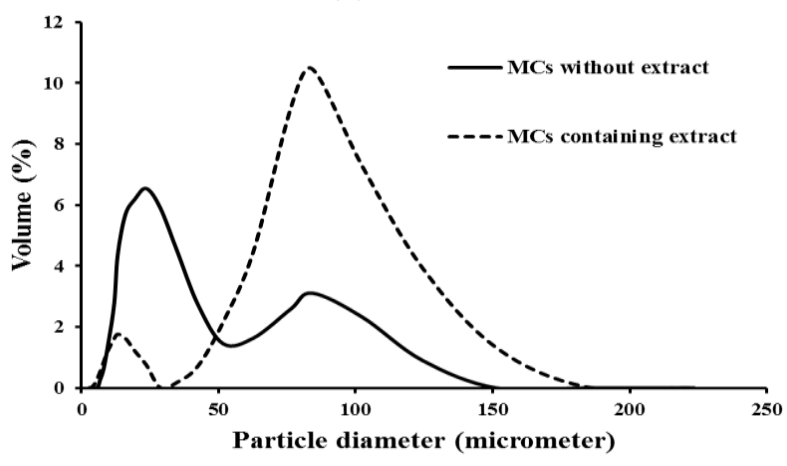

Fig. 3. Particle size distribution of MCs.

\section{B. Characterization of Finished Fabric}

Fig. 4 shows cotton fabric finished with guava leaf extract and MCs containing guava leaf extract by the printing method. The fabric finished with guava leaf extract has a more intense homogeneous brown color and a smoother surface than fabric finished with MCs containing guava leaf extract. For cotton fabric finished with MCs containing guava leaf extract, MCs are deposited on the fabric surface with the assistance of Helizarin and Fixapret F-Eco.

\section{Assessment of Antibacterial Activity}

The finished fabrics were assessed for antibacterial activity against E. coli and $S$. aureus using AATCC147-2004. The results are shown in Fig. 5 and Fig. 6. There is no zone of inhibition in any of the fabrics against $E$. coli. The unfinished cotton fabric is shown by (b), cotton fabric finished with guava leaf extract is (a), and cotton fabric finished with MCs containing guava leaf extract is (c). However, there is no growth of $E$. coli underneath the fabric finished with guava leaf extract and the fabric finished with MCs containing guava leaf extract. 
(a)

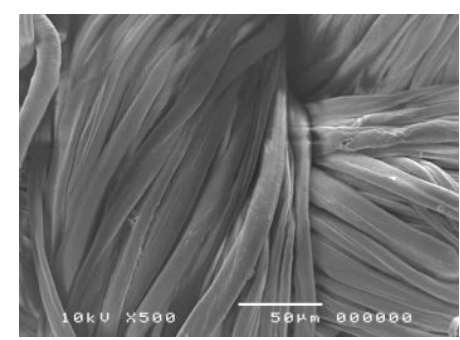

(b)

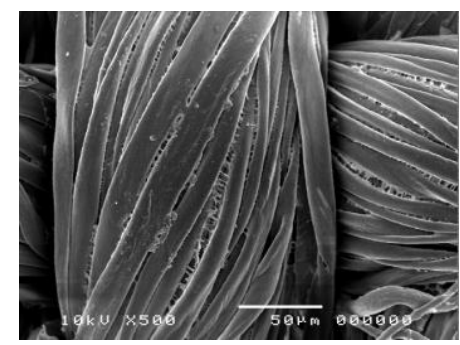

(c)

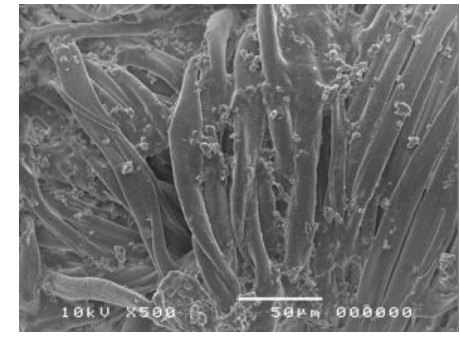

Fig. 4. SEM images of (a) unfinished cotton fabric; (b) cotton fabric finished with guava leaf extract (c) cotton fabric finished with MCs containing guava leaf extract.

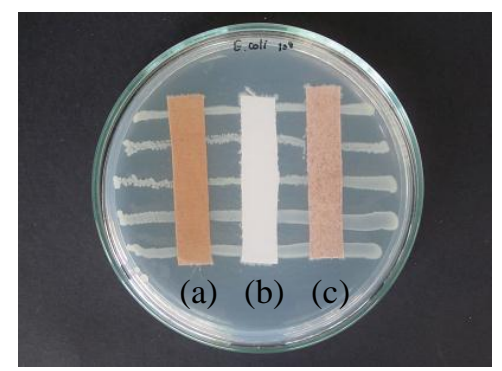

Fig. 5 Antibacterial activity results against E.coli of (a) cotton fabric finished with guava leaf extract; (b) unfinished cotton fabric; (c) cotton fabric finished with MCs containing guava leaf extract.

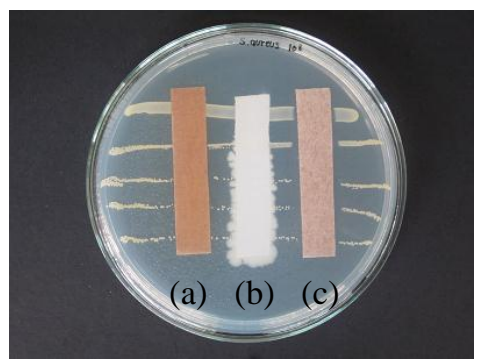

Fig. 6. Antibacterial activity results against S.aureus of (a) cotton fabric finished with guava leaf extract; (b) unfinished cotton fabric; (c) cotton fabric finished with MCs containing guava leaf extract.

Fig. 6 shows the result of antibacterial activity against $S$. aureus. The fabric finished with MCs containing guava leaf extract (C) has an obviously larger zone of inhibition that that of the fabric finished with guava leaf extract (a). The results show that fabric finished with MCs containing guava leaf extract shows good antibacterial activity against $S$. aureus. Although the fabric finished with guava leaf extract has no inhibition zone, S. aureus cannot grow underneath the fabric. This result indicates that cotton fabric finished with MCs containing guava leaf extract can inhibit $S$. aureus better than E. coli.

\section{Effect of Formaldehyde Amount}

Both the fabric finished with extract and the fabric finished with MCs were analyzed for formaldehyde residue according to the BS EN ISO 14184-1:1999 standard. The results showed that the free formaldehyde amount on the fabric finished with extract and MCs was 0.30 and $1.51 \mathrm{ppm} / \mathrm{g}$ of fabric. However, the weight of each sample fabric for antibacterial testing was approximately $0.4 \mathrm{~g}$. Therefore, it can be assumed that the fabric samples contained 0.12 and $0.60 \mathrm{ppm}$ formaldehyde for the cotton fabric finished with guava leaf extract and the cotton fabric finished with MCs containing guava leaf extract, respectively. Thus, it is likely that the amount of formaldehyde did not affect the inhibition of organism growth.

\section{CONCLUSION}

MCs containing guava leaf extract were successfully constructed by in situ polymerization of PUF shells under acidic conditions. The surface morphology of MCs containing guava leaf extract was rough with irregular particles. The formation of MCs confirmed the encapsulation of guava leaf extract in the PUF shells by the intensity of $-\mathrm{OH}$ group in the phenolic compound at $3700-3000 \mathrm{~cm}^{-1}$ and the absorption bands at $1444 \mathrm{~cm}^{-1}$ and $1118 \mathrm{~cm}^{-1}$ which corresponded with the bands in the spectra of guava leaf extract. Finally, cotton fabric finished with MCs containing guava leaf extract showed antibacterial activity against $S$. aureus, but it was not effective against $E$. coli. It can be concluded that guava leaf extract MCs are effective for application as an antibacterial agent for finishing textiles. However, more research needs to be done on wash durability testing and quantitative testing of antibacterial activity.

\section{ACKNOWLEDGMENT}

This work was financially supported by the Office of the Higher Education Commission (OHEC). The authors sincerely thank Uttaradit Rajabhat University for granting Ph.D. study. The instruments for this work were supported by the Applied Chemistry Program, Faculty of Science, Maejo University and Textile Labaratory, Polymer Research Unit, National Metal and Materials Technology Center (MTEC), Thailand.

\section{REFERENCES}

[1] G. Nelson, "Application of microencapsulation in textiles," International Journal of Pharmaceutics, vol. 242, pp. 55-62, February 2002.

[2] L. Ferreira, M. Fonseca, G. Botelho, C. Almeida-Aguiar, and I. C. Neves, "Antimicrobial activity of faujasite zeolites doped with silver," Microporous and Mesoporous Materials, vol. 160, pp. 126-132, September 2012

[3] E. Koh and K. H. Hong, "Gallnut extract-treated wool and cotton for developing green," Dyes and Pigments, vol. 103, pp. 222-227, April 2014.

[4] M. I. Khan, A. Ahmad, S. A. Khan, M. Yusuf, M. Shahid, N. Manzoor and F. Mohammad, "Assessment of antimicrobial activity of Catechu 
and its dyed substrate," Journal of Cleaner Production, vol. 19, pp. 1385-1394, August 2011.

[5] R. M. P. Gutiérrez, S. Mitchell, and R. V. Solis, "Psidium guajava: A review of its traditional uses, phytochemistry and pharmacology," Journal of Ethnopharmacology, vol.117, pp. 1-27, Jan. 2008.

[6] W. Nantitanon, S. Yotsawimonwat, and S. Okonogi, "Factors influencing antioxidant activities and total phenolic content of guava leaf extract," LWT-Food Science and Technology, vol. 43, pp. 1095-1103, Feb. 2010.

[7] R. N. Venkatachalam, K. Singh, and T. Marar, "Phytochemical screening and in vitro antioxidant activity of Psidium guajava," Free Radicals and Antioxidants, vol. 2, pp. 31-36, Jan.-Mar. 2012.

[8] K. F. Chah, C. A. Ezp, C. E. Emuelosi, and C. O. Esimone, "Antibacterial and wound healing properties of methanolic extracts of some Nigerian medical plants," Journal of Ethnopharmacology, vol. 104, pp. 164-167, Oct. 2005.

[9] S. Garcia, M. Araiza, M. Gomaz, and N. Heredia, "Inhibition of growth, enterotoxin production, and spore formation of Clostridium perfringens by extracts of medicinal plants," Journal of Food Protection. vol. 65, pp.1667-1669, Oct. 2002.

[10] H. Umer, H. Nigam, A. M. Tamboli, and S. M. Nainar. (2011) Microencapsulation: process, techniques and applications. International Journal in Pharmaceutical and Biomedical Sciences. [Online]. 2(2). pp. 474-481. Available: http://www.ijrpbsonline.com

[11] M. W. Keller, Healable Polymer Systems, Cambridge, U.K.: Royal Society of Chemistry, 2013, ch. 2.

[12] J. C. Salamone, Polymeric Materials, Salem, MA: CRA Press, 1996, pp. 8496-8501.

[13] C. Sun, Y.-Q. Feng, B. Zhang, X.-G. Li, J.-Z. Shao, J.-J. Han, and X. Chen, "Preparation and application of microcapsule-encapsulated color electrophotic fluid in Isopar M system for electrophoretic display," Optical Materials, vol. 35, pp. 1410-1417, March 2013.

[14] E. S. Abdel-Halim, F. A. Abdel-Mohdy, M. M. G. Fouda, S. M. El-Sawy, I. A. Hamdy, and S. S. Al-Deyab, "Antimicrobial activity of monochlortriazinyl- $\beta$-cyclodextrin/chlorohexidin diacetate finished cotton fabrics," Carbohydrate Polymers, vol. 86, pp. 1389-1394, June 2011.

[15] N. T. Hein, S. S. Hnin, and D. H. Htay, "A study on the effect of antimicrobial agent from Aloe Vera gel on bleached cotton fabric," International Journal of Emerging Technology and Advanced Engineering, vol. 4, pp. 7-11, Feb. 2013.

[16] S. Sharaf, A. Higazy, and A. Hebeish, "Propolis induced antibacterial activity and other technical properties of cotton textiles," International Journal of Biological Macromolecules, vol. 59, pp. 408-416, May 2013.

[17] B. Sudha, M. Dolly, R. Rupali, A. Neha, and S. Sangeeta, "Ecofriendly finishing of fabric with Jatropha Curcas leaves," Research Journal of
Family, Community and Consumer Sciences, vol. 1, pp. 7-9, March 2013.

[18] S. Moussa, A. Ibrahim, A. Okba, H. Hamza, K. Opwis, and E. Schollmeyer, "Antibacterial action of acetic acid soluble material isolated from Mucor rouxii and its application onto textile," International Journal of Biological Macromolecules, vol. 48, pp. 736-741, March 2011.

[19] R. Rajendran, C. Balakumar, J. Kalaivani, and R. Sivakumar, "Dyeability and antimicrobial properties of cotton fabrics," Journal of Textile and Apparel Technology and Management, vol. 7, pp. 1-12, 2011.

[20] A. E. Grice, H. A. Kong, S. Conlan, C. B. Deming, J. Davis, A. C. Young, G. G. Bouffard, R. W. Blakesley, P. R. Murray, E. D. Green, M. L. Turner, and J. A. Segre, Topographical and Temporal Diversity of Human Skin Microbiome, NISC Comparative Sequencing Program: Science, 2009, pp. 1190-1192.

[21] C. Suryanarayana, K. C. Rao, and D. Kumar, "Preparation and characterization of microcapsules containing linseed oil and its use in self-healing coatings," Progress in Organic Coatings, vol. 63, pp. 72-78, April 2008

[22] Antibacterial Activity Assessment of Textile Materials: Pararell Streak Method, AATCC Test Method 147-2004.

[23] Textiles-Determination of Formaldehyde-Part 1: Free and hydrolyzed formaldehyde (water extraction method), ISO 14184-1-1998.

[24] S. J. Park, Y. S. Shin, and J. R. Lee, "Preparation and characterization of microspheres containing lemon oil," Journal of Colloid Interface Science, vol. 241, pp. 502-508, Sep. 2001.

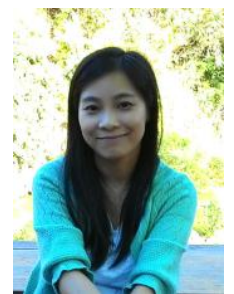

Jiraphorn Katewaraphorn was born in Chumporn, Thailand, in 1982. She received a B.S. degree in chemistry from Naresuan University, Phitsanulok, Thailand, 2004 and an M.S. degree in biotechnology from Chiang Mai University, Chiang Mai, Thailand, in 2010

She is currently a Ph.D. student at Maejo University, Chiang Mai, Thailand. Her major is applied chemistry and her research interest is the encapsulation of natural products and finishing textiles. She published the title of Microencapsulation of Psidium guajava Linn. Leaf Extract in 2013 and Preparation of Microcapsules Containing Sapindus rarak DC. Extract in 2014. In 2007, she worked as an R\&D chemist at Winson Screen Co., Ltd. In 2010, she joined the Program of Applied Chemistry, Faculty of Science and Technology, Rajabhat University, Uttaradit, Thailand, as a lecturer. 